\title{
Survey
}

\section{Major depression in pregnancy and post partum associated with anxiety disorders and substance use}

\section{Debra Kay Creedy, Jenny Gamble ${ }^{2}$}

10.1136/ebnurs-2012-100532

${ }^{1}$ Queensland Centre for Mothers \& Babies, University of Queensland, Brisbane, Australia ${ }^{2}$ School of Nursing \& Midwifery, Griffith University, Queensland, Australia

\section{Correspondence to:}

Debra Kay Creedy

Queensland Centre for Mothers

\& Babies, University of

Queensland, Mansfield Place,

St Lucia, Brisbane QLD 4072,

Australia;

d.creedy@griffith.edu.au

Commentary on: Le Strat Y, Dubertret C, Le Foll B. Prevalence and correlates of major depressive episode in pregnant and postpartum women in the United States. J Affect Disord 2011;135:128-38.

\section{Implications for practice and research}

Women are vulnerable to depression and anxiety during pregnancy and post partum, yet only one in four seek help.

Clinical management of mothers experiencing depression should assess for substance abuse, unmet needs and psychiatric co-morbidities.

Population-based studies can determine prevalence but cause and effect is best shown through intervention-based randomised controlled trials.

Depressed women are less likely to respond to surveys, so using face-to-face and telephone interviews can enhance response rates and completion.

\section{Context}

Pregnancy can trigger a first depressive episode or recurrence of depression for some women. Depressive symptoms of pregnant and post partum women do not differ much from those of depressed women at other times. ${ }^{1}$ Depression adversely affects mood, energy levels, appetite and sleep. Often mothers are emotionally detached and less responsive to infant needs and may harm the infant. $^{2}$ Risk factors include a history of depression, anxiety, stressful life events and lack of social support. ${ }^{2}$ Predominantly, studies have recruited women who are hospitalised or using clinical services rather than the general population. This study uses the general population to examine the prevalence and correlates of major depression in pregnant and post partum women in the USA.

\section{Methods}

Le Strat et al analysed cross-sectional data from 2001 to 2002 National Epidemiological Survey on Alcohol and Related Conditions (NESARC). ${ }^{3}$ NESARC is a face-to-face interview of 43093 adults (response rate of $81 \%$ ) of whom 14549 were women of childbearing age (18-50 years). Of these, 1524 were pregnant at interview, or had been pregnant in the preceding 12 months and are referred to as 'past-year pregnant.' ${ }^{3}$ Diagnoses of depression and other mood disorders, anxiety and drug disorders were based on the Alcohol Use Disorder and Associated Disabilities Interview Schedule - DSM-IV version. ${ }^{3}$

Weighted prevalence estimates and standard errors were computed. Multivariate logistic regressions were conducted. Adjusted ORs and 95\% CIs reflect association strength and significance.

\section{Findings}

Prevalence of major depression was $12.4 \%$ for past-year pregnant women. Depression was associated with younger age, ethnicity, being unmarried, experiencing stressful events in the past 12 months and pregnancy complications. Of these women, $42.7 \%$ had a concurrent anxiety disorder and 35.4\% had nicotine dependence. Similar prevalence was found for depressed, non-pregnant women (45.3\% anxiety and 36.8\% nicotine dependence). Only $10.7 \%$ of non-depressed past-year pregnant women had an anxiety disorder and $11.4 \%$ had nicotine dependence. 
One in four depressed women sought help but this may be related to social inequality and lack of access to care.

\section{Commentary}

Major depression, anxiety and substance use disorders during pregnancy and post partum are underrecognised. History of depression is the strongest risk factor. $^{5}$ Depression at this time impairs mother-infant attachment, and increases the risk for maternal self harm and suicide. ${ }^{5}$

This study has several strengths: (1) the sample is large and representative, (2) unique comparisons were possible for depressed and non-depressed past-year pregnant women, as well as depressed and nondepressed women of childbearing age and (3) adjustments were calculated for oversampling and household and person-level non-response.

Diagnostic interviews were conducted by trained interviewers and are likely to be more accurate than selfreport but not as rigorous as clinical interviews. Interviews minimise the likelihood of items being misunderstood and incomplete responses. Measures used were valid and reliable. Although a recognised algorithm was used to determine 'any substance use disorder', there were weaknesses in other measures; 'any substance use' was retrospective (past 12 months) and aggregated; and 'complications during pregnancy or delivery' and health status were also single self-report items. This may have contributed to over-reporting and limit clinical significance.

NESARC was conducted during 2001 and 2002. In the decade since, there has been greater awareness of risk factors, and developments in care such as screening, and evidence-based interventions to assist women. Attention also needs to be given to women experiencing depression that does not meet the full diagnostic criteria as they may suffer considerable distress and require treatment. $^{5}$ Young women under 18 years were not included in the survey, yet this cohort have high rates of substance use (especially cigarettes) and are vulnerable to depression and anxiety during pregnancy. Future surveys should also determine the health needs of this younger group.

\section{Competing interests None.}

\section{References}

1. Manber R, Blasey C, Allen JJ. Depression symptoms during pregnancy. Arch Womens Ment Health 2008;11:43-8.

2. Lee DTS, Chung TKH. Postnatal depression: an update. Best Prac Res Clin Obstet Gyn 2007:183-91.

3. Grant BF, Moore TC, Kaplan K. Source and Accuracy Statement: Wave 1 NESARC. Bethsda, Maryland: National Institute on Alcohol Abuse and Alcoholism, 2003.

4. Vesga-López 0, Schneier FR, Wang S, et al. Gender differences in generalized anxiety disorder: results from the National Epidemiologic Survey on Alcohol and Related Conditions (NESARC). J Clin Psychiatry 2008;69:1606-16.

5. Goodwin RD, Keyes KM, Stein MB, et al. Peptic ulcer and mental disorders among adults in the community: the role of nicotine and alcohol use disorders. Psychosom Med 2009;71:463-8.

6. Stewart DE. Clinical practice. Depression during pregnancy. N Engl J Med 2011;365:1605-11. 


\section{Major depression in pregnancy and post partum associated with anxiety disorders and substance use}

Debra Kay Creedy and Jenny Gamble

Evid Based Nurs 2012 15: 104-105 originally published online June 29, 2012

doi: 10.1136/ebnurs-2012-100532

Updated information and services can be found at:

http://ebn.bmj.com/content/15/4/104.full.html

These include:

References This article cites 5 articles, 1 of which can be accessed free at: http://ebn.bmj.com/content/15/4/104.full.html\#ref-list-1

Email alerting Receive free email alerts when new articles cite this article. Sign up in service the box at the top right corner of the online article.

$\begin{array}{cc}\text { Topic } & \text { Articles on similar topics can be found in the following collections } \\ \text { Collections } & \text { Pregnancy (187 articles) } \\ \text { Reproductive medicine (258 articles) } \\ \text { Mood disorders (including depression) (68 articles) } \\ \text { Child and adolescent psychiatry (125 articles) } \\ \text { Child and adolescent psychiatry (paedatrics) (125 articles) } \\ \text { Anxiety disorders (including OCD and PTSD) (6 articles) } \\ \text { Child abuse (32 articles) } \\ \text { Drugs misuse (including addiction) (68 articles) } \\ \text { Health effects of tobacco use (39 articles) } \\ \text { Smoking (145 articles) } \\ \text { Suicide (psychiatry) (28 articles) } \\ \text { Suicide (public health) (28 articles) }\end{array}$

Notes

To request permissions go to:

http://group.bmj.com/group/rights-licensing/permissions

To order reprints go to:

http://journals.bmj.com/cgi/reprintform

To subscribe to BMJ go to:

http://group.bmj.com/subscribe/ 